\section{Universities win as South Africa reverses 1997 funding trend}

[CAPE TOWN] Research seems to have fared badly in South Africa's budget this year, at first glance. Nominally, it has decreased by four per cent from 1,116 million rand (US $\$ 219$ million) to R1,074 million - a decline of ten per cent in real terms after inflation is taken into account.

But science and engineering university researchers are pleased that the agency that funds research in their fields in the tertiary education sector, the Foundation for Research Development (FRD), received a budget rise of 28 per cent. This increase comes out of the science vote awarded though the Department of Arts, Culture, Science and Technology.

The allocation to universities reverses the trend in last year's budget, when the two largest councils responsible for 'in-house' research, the Council for Scientific and Industrial Research (CSIR) and the Agricultural Research Council (ARC), received increases of 19 and 11 per cent respectively (see Nature 386, 425; 1997).

This year both these councils had their budgets cut - by one per cent for the CSIR and 35 per cent for ARC, which has been the most severely affected.

The change has been welcomed in university circles. Renfrew Christie, dean of research at the University of the Western Cape, says it is essential that more research funds be allocated to agencies serving the higher education sector, as they are able to use them more efficiently.

The ARC has had to respond to its budget cut by terminating many projects and, in some instances, laying off staff members, according to Nico Human, its group executive for marketing and public relations.

He says the council has been successful in obtaining alternative sources of funding for some projects. But Christie counters that the ARC budget cut is both "long overdue" and not enough, describing it as an "unforgivably inefficient institution".

The FRD is using most of its increased funding to double its allocation to tertiary education institutions to buy research equipment, and to grant a 38 per cent funding increase to its programme of boosting research in 'historically disadvantaged' institutions.

The FRD also succeeded in obtaining an additional R50 million through the Department of Trade and Industry to fund its programme on technology and human resources for industry. This programme, which helps to set up partnerships between industry and universities or technical colleges, has attracted an additional R70 million from the private sector this year.

Michael Cherry

\title{
Bid to limit prices on drugs using 'public' discoveries
}

[WASHINGTON] The US biotechnology industry has launched a strongly worded attack on a congressional bill that seeks to restrict the prices that pharmaceutical companies can charge for products based on federally funded biomedical discoveries.

The bill would require companies that enter research collaborations with government agencies, or exclusively license rights from them, to sign a 'reasonable pricing agreement' for any products that result. The same requirement would apply to agreements between companies and government grantees, such as universities.

The bill reawakens a debate from 1995, when Harold Varmus, the director of the National Institutes of Health (NIH), removed a 'reasonable pricing' clause that had been included since 1989 in cooperative research and development agreements and exclusive licences negotiated between the $\mathrm{NIH}$ intramural programme and industry (see Nature 374, 669; 1995).

The new bill, introduced last month, is sponsored by Bernard Sanders (Independent, Vermont). It has been broadly expanded from earlier versions, first introduced in 1995, which would have applied only to agreements with industry negotiated by the NIH.

Known as the Health Care Research and Development and Taxpayer Protection Act, the new bill would prohibit federal agencies that fund biomedical research - and nonprofit institutions that receive funds from them - from entering collaborations or exclusive licensing agreements unless the company involved "first agrees to a reasonable pricing agreement with the Secretary of Health and Human Services".

To arrive at a reasonable price, the bill says, the secretary should use a competitive bidding process where reasonable, but may waive the requirement if this would serve "the public interest".

Supporters of the bill — which has 14 cosponsors, from liberal Democrats to conservative Republicans - say that it is intended to prevent drug companies from making enormous profits on products that owe their existence to government research funded by taxpayers. "There's profit, and then there's profiteering," says an aide to Fortney 'Pete' Stark (Democrat, California), a co-sponsor.

Sanders, who is the lead sponsor, calls current practice "insane". The NIH is "giving the right to drug(s) over to the private sector with no negotiations whatsoever," he says. "If the federal government has added value to the process, it is worth something; you cannot give it away."

Sanders cites the example of AZT, the first anti-AIDS drug, the development of which

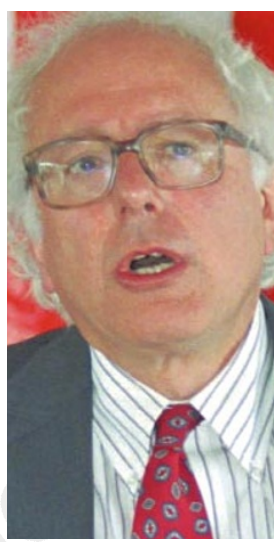

Sanders: reawakening debate from 1995. was supported by the National Cancer Institute. BurroughsWellcome (now Glaxo Wellcome) launched the drug in 1987 at a cost of $\$ 10,000$ per patient per year, prompting the NIH patent policy board in 1989 to require reasonable pricing clauses in agreements between the NIH intramural programme and industry.

But the bill has upset the Biotechnology Industry Organization (BIO). "It would have an adverse impact on every single relationship that the government and its grantees have with the research and development companies," says Chuck Ludlam, a BIO lobbyist, who points out that the bill targets universities as well as the NIH.

Karen Hersey, president of the Association of University Technology Managers, which represents technology transfer professionals, says that a pricing clause would cause companies to shun agreements with the NIH and other agencies, leaving valuable government research sitting on the shelf.

It would be "enormously detrimental" to the commercialization of NIH-funded research, says Hersey, who is the intellectualproperty counsellor at the Massachusetts Institute of Technology. Mark Grayson, a spokesman for the Pharmaceutical Research and Manufacturers of America, agrees. Reasonable pricing clauses, he says, "reduce the reward for collaborating and in the end they stifle innovation."

Although Congress-watchers predict that Sanders' bill will not travel far in a Republican-dominated Congress, it has generated considerable attention. For example, it was featured in the Boston Globe newspaper last month and has been covered on the NBC television programme Nightly News.

Ludlam says that BIO is taking the bill "very seriously" for two reasons. First, it has grown in popularity in Congress, where it failed to pass the House of Representatives in 1996 by only 62 votes, as an amendment to the bill funding the NIH. (It was not brought up for a vote in 1997.) Second, he says, even if the bill does not pass this year, the prospect that it might do so in the near future could deter companies from entering into research agreements with universities and government agencies.

Meredith Wadman 